\title{
Patients with foot skin diseases may be susceptible to infection of HPV
}

\author{
Xiaomin Zhang ${ }^{1}$, Tangde Zhang $^{2}$ and Yanhua Liang ${ }^{3 *}$ \\ ${ }^{1}$ Department of Dermatology and STD, Changping Hospital of Jinan University, Dongguan, China \\ ${ }^{2}$ Department of Dermatology and STD, Zhujiang Hospital of Southern Medical University, Guangzhou, China \\ ${ }^{3}$ Department of Dermatology and STD, Shenzhen Hospital of Southern Medical University, Shenzhen, China
}

\begin{abstract}
Background: Cutaneous viral warts (non-genital) is an intractable disease, which are caused by infection with a type of Human Papilloma Virus (HPV). The virus is believed to enter the body through skin that has been damaged slightly. The other skin diseases which adjacent to cutaneous viral warts and destroy the skin barrier function may influent the prognosis of the warts.
\end{abstract}

Objective: Classifying the other skin diseases in cutaneous viral warts and assessing their possible association with different kinds of cutaneous viral warts.

Methods: Culling Center database from our hospital between May 2016 and May 2017, we retrospectively reviewed patients in whom "warts" had been diagnosed, and then calculated the other skin diseases adjacent to the warts.

Results: 991 cases were assessed in the final analysis, including 230 plantar warts, 153 plane warts and 604 common warts, with which there are 143 , 8 and 34 cases of skin diseases adjacent to them, respectively. The incidence of the skin diseases adjacent to plantar warts is much higher than in the other two type of warts. The number of treatments of the plantar warts which was combined with other foot disease is higher than that with no other foot diseases.

Conclusions: Patients with foot skin diseases may be susceptible to infection of HPV.

Limitation: A potential limitation to this study is sampling bias and lack of generalizability; this study was performed at district center hospital in China. Additional studies are needed to determine how these adjacent diseases change over time with various therapies.

\section{Introduction}

Cutaneous viral warts (non-genital) are one of the most common infectious skin disease, of which the prevalence in the general population is estimated to be $7-12 \%$ [1]. Many patients present to primary care with pain and discomfort along with other concerns, such as cosmetic appearance [2]. Warts is a cutaneous manifestation of the Human Papillomavirus (HPV), which appears as benign epithelial tumors with hard, thickened skin. There are three kinds of warts have been identified, varying in shape and site affected, they are plane warts, plantar warts and common warts [3].

Despite the presence of several therapeutic options [4-6], treatment of warts can occasionally present a therapeutic challenge and none of them is uniformly effective, leading to possible relapses after initial healing. It is unknown whether HPV has the ability to penetrate intact skin [7]. Micro trauma certainly facilitates access of the virus to the deeper layers of skin, as evidenced by the predilection of warts for injuries [8]. Since non-intact skin may increases the risk for affection of HPV, the combination of other skin diseases abject to the warts that destroy the skin barrier function may have an impact on the prognosis and the natural course of warts, but anecdotal evidence suggests that few dermatologists are aware of them. Therefore, in this article, we want to classify the other skin diseases in cutaneous viral warts and assess their possible association with different kinds of cutaneous viral warts.

\section{Methods}

We conducted a retrospective study of patients with cutaneous viral warts seeking treatment at the dermatology clinic in Changping Hospital of China, between May 2016 and May 2017. The study was reviewed and approved by the Board of Changping Hospital in China.

Data concerning individual information, diagnoses and treatment were collected. In this study, we just concerned the cases in which the treatment was liquid nitrogen therapy only. The diagnoses could be verruca vulgaris, common warts, verruca plana, flat wart, plane warts, plantar warts or warts. Patients were excluded if the diagnosis was genital warts or other diagnoses which were contained "warts", such as "molluscum contagiosum" in Chinese. The uncertainty diagnoses were also excluded.

Analyses were processed with the available data and the number available for each analysis is stated where data were absent from the clinical record. Data were analyzed using a personal computer with

Correspondence to: Yanhua Liang, Department of Dermatology and STD, henzhen Hospital of Southern Medical University, Shenzhen, China, E-mail: liangdoctor@163.com

Key words: viral warts, adjacent, $H P V$

Received: February 02, 2018; Accepted: February 26, 2018; Published: February 28,2018 
“(SPSS) version 22" program. We compared the baseline characteristic of the three groups by General Linear Model in mean age, and the incidence by K Independent Samples test. Chi-square test were used for comparison of treatment course. $\mathrm{P}$ values $<0.05$ was considered as statistically significant.

\section{Results}

4347 potentially relevant cases were identified through database. 991 cases trials were assessed in the final analysis, including 230 plantar warts, 153 plane warts and 604 common warts (Figure 1).

The result of the analyses showed that there is no statistically significant difference in age and sex among the three groups $(>0.05)$. There was a statistically significant difference in the proportion of children $(<0.05)$. The incidence of the diseases adjacent to plantar warts, plane warts and common warts is $62 \%, 0.05 \%$ and $0.06 \%$, respectively. The comparison of incidence among the three groups is statistically significant different. The number of treatments of the plantar warts which was combined with other foot disease is higher than that with no other foot diseases, but there was not a statistically significant difference in the treatment course between them $(>0.05)$. The result of the main study characteristics and data are listed in Tables 1,2 and Figure 2.

\section{Discussion}

Mostly, vital warts (not genital) are a field of benign hyperkeratotic papillomas that is caused by infection of HPV, and destruction of the lesion itself cannot directly clear the infection. The ensuing inflammation, however, helps to recruit the immune system into the area [4], therefore, the other skin diseases adjacent to the warts may influence the immune response.

Though the comparison of incidence and number of treatments among the three groups is not statistically significant different. The result may be the error caused by the imbalance between the samples. 604 cases were identified in the common warts groups while 230 and

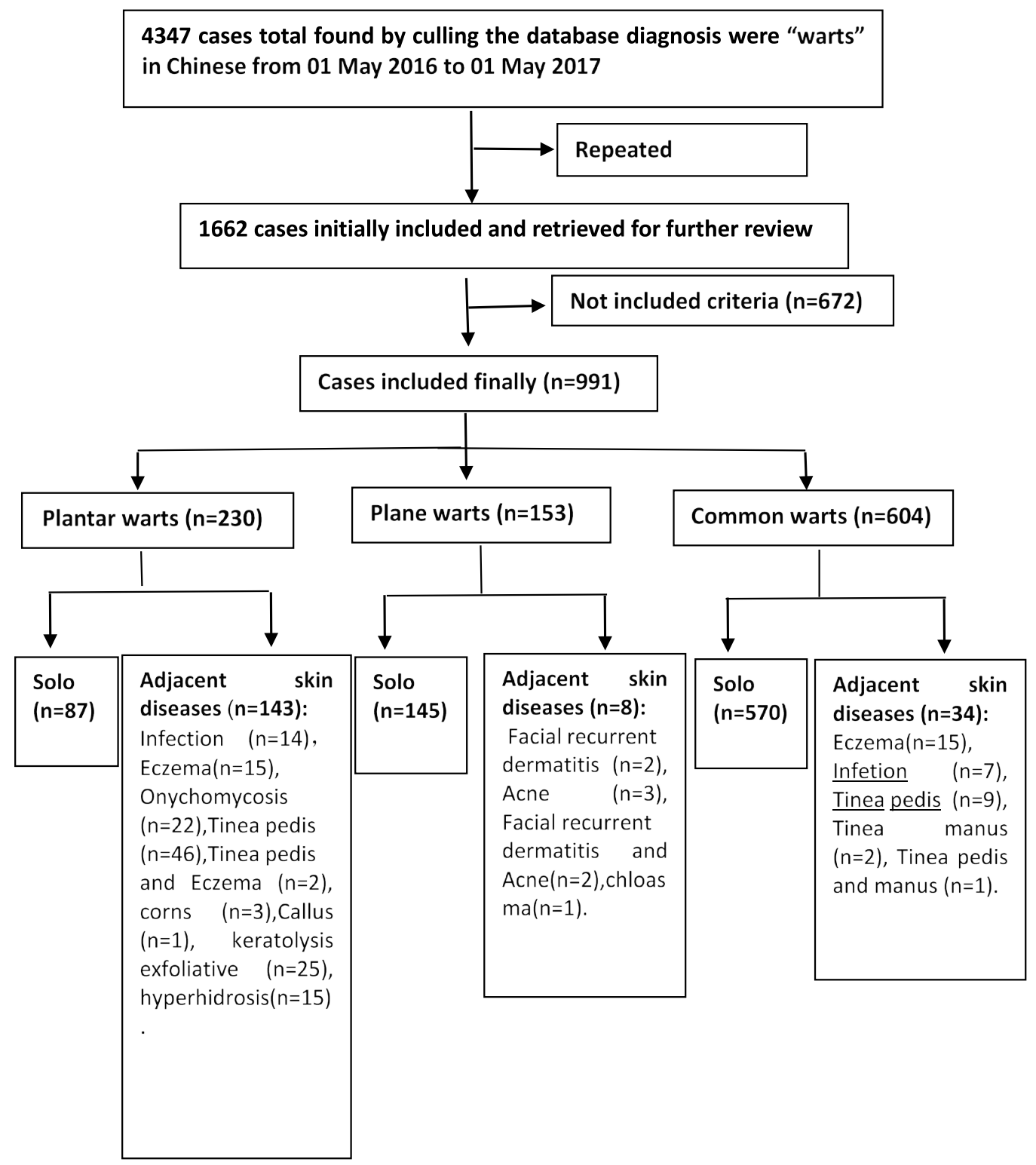

Figure 1. Study flow diagram 


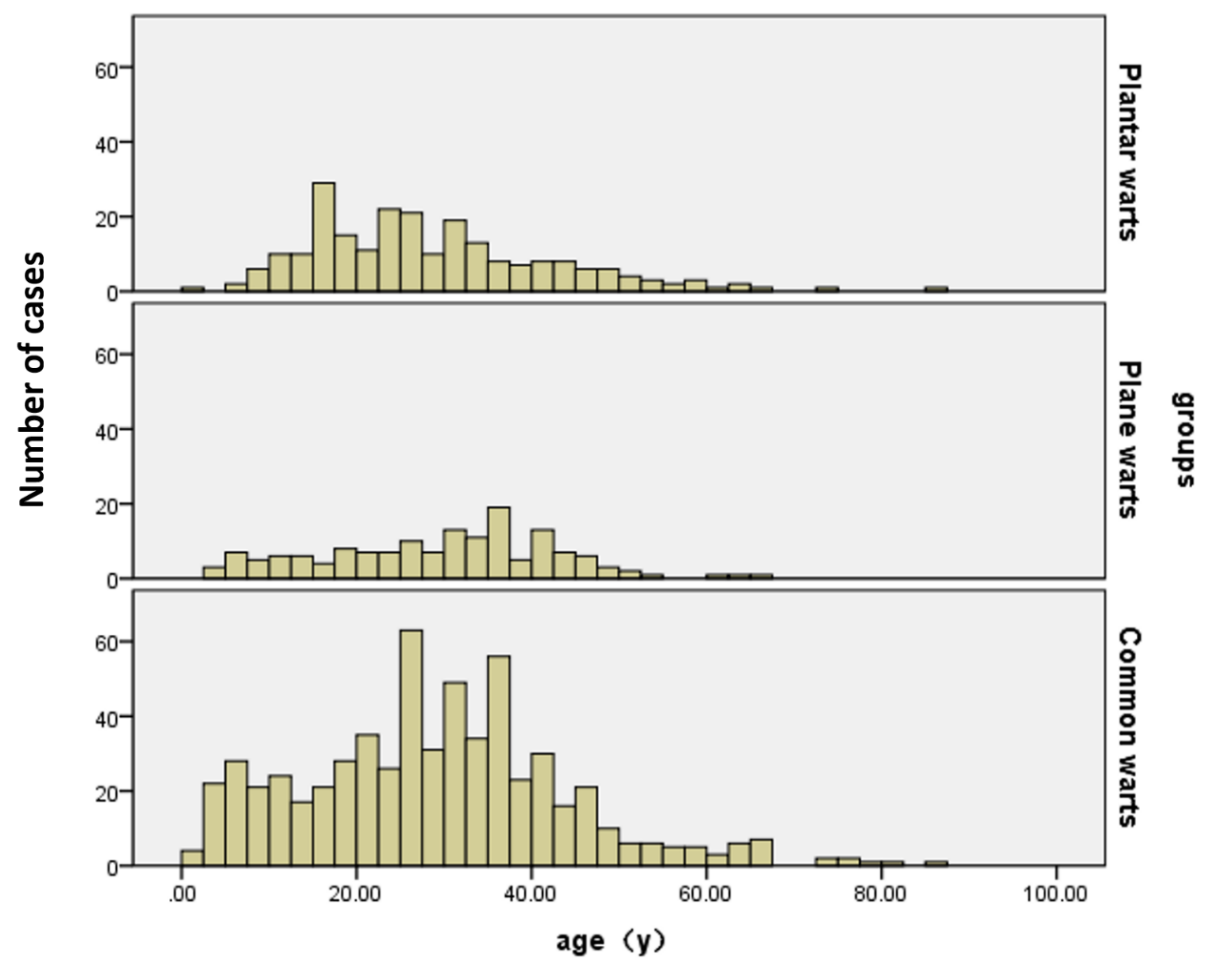

Figure 2. Characteristic of the three groups

Table 1. Baseline Characteristics

\begin{tabular}{|c|c|c|c|c|}
\hline Characteristic & Plantar warts & Plane warts & Common warts & P value \\
\hline Mean age, y (SD) & $28.39(13.76)$ & $29.30(13.15)$ & $28.80(15.03)$ & $>0.05$ \\
\hline Children, $<14 y(\%)$ & $26 / 230=11 \%$ & $26 / 153=17 \%$ & $108 / 604=18 \%$ & $<0.05$ \\
\hline Male sex, \% & $126 / 230=55 \%$ & $72 / 153=47 \%$ & $354 / 604=59 \%$ & $>0.05$ \\
\hline Comorbidity, \% & $143 / 230=62 \%$ & $8 / 153=0.05 \%$ & $34 / 604=0.06 \%$ & $>0.05$ \\
\hline
\end{tabular}

Table 2. Numbers of liquid nitrogen therapy

\begin{tabular}{|c|c|c|c|}
\hline & Solo & Comorbidity & Total \\
\hline Plantar warts & 3.2 & 9.7 & 12.9 \\
\hline Plane warts & 2.9 & 2.7 & 5.6 \\
\hline Common warts & 4.2 & 3.9 & 8.1 \\
\hline Total & 10.3 & 16.3 & 26.6 \\
\hline
\end{tabular}

153 cases were reported in the other two groups. The incidence of the diseases adjacent to warts were similar in both plane and common warts. The incidence of the diseases adjacent to plantar warts is $62 \%$, which is much higher than $0.05 \%$ and $0.06 \%$ in the other two types of warts. This result may relevant to the poor skin hygiene of the foot, also, children are preferring to be barefoot that make the foot easy to get hurt my micro trauma.

The outlook of plane warts are different from other two kinds of warts, this may be associated with the type of HPV being affected [8]. Our results also show that there are fewer skin diseases adjacent to the plane warts. This finding may suggest that the mechanism of plane warts are different from other two kinds of warts.

Identify whether the other skin diseases adjacent to the warts will increases the risk for affection of HPV or prolong the duration of the warts and find the relationship between them may improve treatment results, reduce costs, and limit the burden of side-effects.

Our results suggested that the general condition of surrounding skin has some influence on the duration of the warts. Further studies should be conducted to confirm the relationship between the onset of the warts and the duration of the surrounding skin disease and to examine whether the treatment of the surrounding skin disease will prolong the duration of the cutaneous vital warts, or, whether these diseases could influence the natural course or response to treatment of warts.

\section{References}

1. Lynch MD, Cliffe J, Morris-Jones R (2014) Management of cutaneous viral warts $B M J$. [Crossref]

2. de Koning MN, Quint KD, Bruggink SC, Gussekloo J, Bouwes Bavinck JN, et al. (2015) High prevalence of cutaneous warts in elementary school children and ubiquitous presence of wart-associated HPV on clinically normal skin. Br J Dermatol 172: 196-201. [Crossref]

3. Bruggink SC, Gussekloo J, de Koning MN, Feltkamp MC, Bavinck JN, et al. (2013) HPV type in plantar warts influences natural course and treatment response: Secondary analysis of a randomised controlled trial. J Clin Virol 57: 227-232. [Crossref]

4. Fox PA, Tung MY (2005) Human Papillomavirus, Burden of Illness and Treatment Cost Considerations. Am J Clin Dermatol 6: 365-381. [Crossref]

5. Pasquali P, Freites-Martinez A, Gonzalez S, Spugnini EP, Alfonso Baldi (2017) Successful treatment of plantar warts with intralesional bleomycin and electroporation: pilot prospective study. Dermatol Pract Concept 7: 21-26. [Crossref]

6. Pasquali P, Freites-Martinez A, Gonzalez S, Onsun N (2017) Effectiveness and safety profile of $40 \%$ trichloroacetic acid and cryotherapy for plantar warts. Dermatol Pract Concept 7: 21-26. [Crossref]

7. Lazarezyk M, Cassonnet P, Pons C, Jacob Y, Favre M (2009) The EVER proteins as a natural barrier against papillomavirus, a new insight into the pathogenesis of human papillomavirus infections. Microbiol Mol Biol Rev 73: 348-370. [Crossref]

8. Bruggink SC, de Koning MN, Gussekloo J, Egberts PF, Ter Schegget J, et al (2012) Cutaneous wart-associated HPV types: Prevalence and relation with patient characteristics. J Clin Virol 55: 250-255. [Crossref]

Copyright: (C2018 Zhang X. This is an open-access article distributed under the terms of the Creative Commons Attribution License, which permits unrestricted use, distribution, and reproduction in any medium, provided the original author and source are credited. 